\title{
Competency Levels of Teachers in Using Interactive Whiteboards
}

\author{
Serkan Celik \\ Kirikkale University, Turkey
}

\begin{abstract}
The interactive whiteboards (IWB) has now been incorporated into the Turkish schools and educational institutions with the launch of the Fatih Project. This article first described the adaptation of a self-efficacy scale on IWB use in Turkish. The secondary aim of the study was to report the self-efficacy levels of primary school teachers toward the technology and the use of IWB in teaching. The participants of the current research were selected on a non-random basis among the primary schools in Kirikkale having at least one designated classroom with IWB. The adaptation studies of the scale including 19 items revealed that it possessed two factors which were implied as common and specific tools of IWBs. The results suggested that the confidence levels of the participant teachers in using IWB tools and features were observed as not satisfactory. This research is expected to serve as a basis for further IWB related studies and contribute to enhancing opportunities to utilize current technologies within the Turkish educational contexts.
\end{abstract}

Keywords: Interactive whiteboards; New educational technologies; IWB; Teachers' selfefficacy in the use of technology; Fatih Project

\section{Introduction}

Currently, most societies put efforts to exploit technology in education for the sake of improving students' learning performances. The rationale under this attempt is that technology not only provides learners with the opportunity to control their own learning process but also enables them to get access to a vast amount of information over which the tutor has little intervention (Gulbahar, 2007; Lam \& Lawrence, 2002). As one of the emerging educational technologies in practice, interactive whiteboards (IWBs) have become popular teaching and learning tools, especially in primary school classrooms (Littleton, 2010; Littleton et al. 2007). IWBs were initially developed for and used in the business sector but they eventually imbedded in education (Murphy, Jain, \& Spooner, 1995; Stephens, 2000). The adoption of IWBs in classrooms at various levels of educational institutions has increased significantly in recent years, and this trend has drawn attention from a growing number of governments around the world. In developed and developing countries, such as Australia, the United Kingdom (UK), the United States (US), and South Africa, an outstanding amount of money has been invested in education sectors for purchasing IWBs (Hall \& Higgins, 2005; Holmes, 2009; Slay, Siebörger, \& Hodgkinson-Williams, 2008; Torff \& Tirotta, 2010). A survey published in 2008 shows that $98 \%$ of secondary and $100 \%$ of primary schools in the UK had IWBs in 2007 (Becta, 2008). In Taiwan, under the "Integration of ICT in classroom teaching" initiative, the Ministry of Education and National Science Council allocated a significant amount of money in IWB equipment and installed it in more than 100 elementary and 
secondary schools' classrooms in 2007 (Lai, 2010). Similar to those countries mentioned above, Turkish Ministry of National Education has recently initiated a project called 'Fatih ' which aims to enhance learning opportunities by integrating latest educational technologies in educational settings throughout the country. Among many objectives, the project involves renovating 40.000 schools and 620.000 classrooms throughout the country by replacing classic educational materials with ICT based hardware such as IWBs with touchable pens, PCs, multifunctional copying devices etc. One of the most attentive goal of the project is to provide all students with tablet PCs and train the classroom practitioners on these technologies through professional development programs which will be held by ICT experts. Students will be supported via online resources to handle their assignments and tasks. The total economic growth of the project is estimated as 8 billion dollars in total.

As one of the vital components of the Fatih project, much has been written about the use of IWBs in particular subject areas in classrooms (Kennewell, Tanner, Jones, \& Beauchamp, 2008; Quashie, 2009; Schmid, 2006, 2008; Troff \& Tirotta, 2010; Zevenbergen \& Lerman, 2008), and pedagogical benefits and pitfalls of this new tool though (Glover, Miller, Averis, \& Door, 2005; Smith et al. 2005; Slay et al. 2008), no substantial evidence is available focusing on the actual competency levels of teachers in the Turkish primary education context while there is a big effort of their implementation into the active teaching. Aside from the research conducted from the perspectives of learners in IWB settings (Turel, 2011), the local research generally focused on either the potentials and drawbacks of the integration of the medium (Somyurek, Atasoy, \& Ozdemir, 2009; Turel \& Demirli, 2010) or the perceptions of teachers toward IWB use (Erduran \& Tataroglu, 2010; Saltan, Arslan \& Gok, 2010). Apart from the adaptation of a self-efficacy scale for teachers on IWB use, the aim of this study is to investigate classroom practitioners' perceptions and self-efficacy levels toward IWB within the Turkish primary education settings. It is hoped that the results of the research will contribute to identifying practical implications in developing better IWB training programs for educators.

\section{IWBs in Learning Process}

Implementing IWBs in actual teaching may provide new enhancements for the learners such as articulating scientific knowledge and getting feedback both from teacher and peers, expressing ideas verbally or graphically. The IWB also provides collaborative opportunities for reasoning, hypothesis testing, and interpretation (Hennessy, Deaney, Ruthven, \& Winterbottom, 2007). Admittedly, learning becomes more effective and enjoyable when learners experience the subject matter by touching and moving objects, seeing the materials from different points of view, watching films and videos, hearing various sounds and musical instruments.

Studies from recent literature report on high levels of student motivation, teacher enthusiasm and wholeschool support associated with IWB related technological tools (Northcote \& Marshall, 2010). Some of the benefits of integrating such technology into classroom instruction include: meeting the needs of visual learners; more interactively teaching whole-class lessons; better engaging students (Wall, Higgins, \& Smith, 2005); and using a variety of multimedia within a whole-class lesson--such as video, pictures, diagrams, and websites (Ekhami, 2002; Higgins, Beauchamp, \& Miller, 2007; Johnson, 2002; Levy, 2002). Smith et al., (2005) mentions about six major benefits of IWBs for teaching process including flexibility and versatility, multimedia/multimodal presentation, efficiency, support planning and development of resources, modeling ICT skills, and interactivity and participation in lessons. Hennessy et al., (2007) stated that IWBs are capable of providing "collaborative opportunities for reasoning, 
hypothesis testing, and interpretation that go beyond those afforded by more established classroom devices" (p. 284). The above mentioned arguments suggest that the potential use of IWB technology in teaching is capable of fostering pedagogical change (Glover et al. 2005).

The growing popularity of IWBs extended the expectations toward their use in classrooms (Dwyer, 2007). Hooper and Rieber (1995) propose some non-hierarchical levels of technology adoption that teachers experience: (1) familiarization; (2) utilization; (3) integration; (4) reorientation; and (5) evolution. At the familiarization level, the teacher is expected to observe and appreciate IWBs, and tends to utilize them for demonstration purposes. At the utilization level, the teacher starts using the IWB in as an alternative to previously used teaching strategies and resources. The integration level involves incorporation of IWBs into practice in an efficient manner. At the reorientation level, teachers masters the tool alongside their students. The evolution level focuses on IWB as an adaptive tool and its use to respond to students' needs by the teacher.

Interactivity is considered as vital for learning and sustained interest (Higgins, Beauchamp, \& Miller, 2007), and is the core point of a number of studies related to IWB technologies (CutrimSchmid, 2008; Levy, 2002; Littleton, 2010). The notion of pedagogic interactivity within the IWB context (Smith et al. 2005) is related to 'interactive teaching', where teachers use higher order questioning and students' active contributions are valued as they test their understanding against collective meaning (Jones \& Tanner, 2002). The concept of IWB interactivity refers to learners' physical movement, cooperation, collaboration and competition. The inclusion of audio and visual resources and the IWB's ability to make digital objects movable may be important in getting the students to interact with the board, with each other, and with the teacher (Xu \& Moloney, 2011). Hennessy et al., (2007) put the emphasis on the fact that IWB interaction is about shared cognition, especially in the articulation, collective evaluation and reworking of the students' own ideas, and coconstruction of new knowledge. Since the use of IWBs is still in the early stages for many classroom teachers and researchers, whether or not IWBs are actually being used as interactive resources is a question that has not yet been fully substantiated by past research (Northcote \& Marshall, 2010).

\section{Teachers of IWB Classes}

In general, IWB is controlled mostly by teachers during the class meeting, and the occurrences of interaction depend on teachers' competences and planning which can invoke teacherstudent and student-student interactions (Glover et al., 2005; Kennewell et al., 2008). The critical role of teacher in IWB settings have been underlined by Wood and Ashfield (2008) who undertook a study involving observations and interviews with teachers and initial teacher education students using IWBs in the UK. Similar thoughts were articulated by Wu and Lin (2009), who investigated three experienced elementary school teachers' perceptions toward IWB use in Taiwan. Their research findings indicated that the IWB's highly interactive features and teachers' involvement in designing class activities helped students to better conceptualize new knowledge through exposure to vivid representations of abstract ideas.

Research posits that teacher choice of technology is often related to their own conceptions of teaching and learning (Glover \& Miller, 2001; Niederhauser \& Stoddart, 2001; Olson, 2000), and introducing new technology does not mean radical pedagogical transformation (Hennessy et al., 2005; Kerr, 1991). Relatively, teachers' preparedness affect the effectiveness of 
technology-enabled learning environments. In this respect, having an IWB in the classroom does not necessarily mean higher levels of student accomplishment. In this regard, Glover and Miller (2001) have pointed out that the teachers` attitude towards technology play a vital role in effective technology integration. They identified the following three types of teachers with different attitudes towards the adoption of IWB's: "Missioners" - those who are interested in new technologies, use them on regular basis in their teaching and try to convince others to use them too, "Tentatives" - those who underwent some training, have access to rooms with IWB but are somehow afraid of them, and "Luddites" -those are the technophobes who underwent training but are afraid of everything new and do not want to waste their time and energy.

Regarding teachers' perspectives on IWB as a teaching tool, Gray et al. (2005) investigated language teachers' perspectives of integrating IWB into their instruction practice. Participants reported that use of IWB enhances teaching greatly by supporting classroom management, pace and variety and drawing attention to the grammatical features and patterns. Participants also felt that use of the IWB had very positive effects on students' memorization skills and writing development. As IWB teaching systems are in their primitive stage in the Turkish context (Baran, 2010), teachers' actual use and teaching efficacy need to be evaluated (Glover, Miller, Averis, \& Door, 2007; Higgins, Beauchamp, \& Miller, 2007)

Holmes (2009) underlines that providing appropriate training for teachers is one of the most important factors in the effective use of IWBs in teaching. As IWBs are a relatively novel teaching resource, there is also a need for teachers to build up a range of multimedia teaching materials and for teachers to understand that initially this process can be quite time consuming. Teachers may also become alert to the new level of presentation expectations Thus, prior to IWBs are well utilized in the classroom, an investment of time and energy to train teachers is required. In addition to feeling confident in using IWBs, teachers need to understand the technical issues associated with maintaining IWB based pedagogical profits. In general, training is usually given by companies or suppliers at the beginning stage of IWB installation, which might be enough for already confident ICT teachers but it is not adequate for most novice adopters (Smith et al., 2005). In other words, additional formal training sessions and informal learning channels should be arranged to make sure that teachers catch the practical use of IWBs. The current study set out to determine how competent the primary level teachers in having the skills needed for a successful implementation of interactive whiteboards and related components such as slates and voting devices into the classroom teaching. The research questions of the study were determined as follows:

1. What are the validity rates of the IWB use confidence scale in Turkish?

2. How do primary level teachers perceive their competency levels in using current technologies for teaching?

3. How do primary level teachers perceive their competency levels in using IWB for teaching?

\section{Methods}

\section{Participants}

The current study was set out to investigate primary school teachers' perceptions and selfreported competencies toward IWB use in teaching. The participant group consisted of 252 
teachers employed at 13 primary education settings in Kirikkale, Turkey. 320 questionnaire forms were distributed to the teachers via school administrations and it took three weeks to get back 252 forms. The basic criteria of choosing schools were whether there is any IWBs in working condition and open to the use of teachers. The general features of the participants are demonstrated in Table 1.

Table 1. Demographic and Occupational Features of the Participated Teachers

\begin{tabular}{llrr}
\hline Gender & & $f$ & $\%$ \\
\hline & Male & 139 & 55.2 \\
& Female & 113 & 44.4 \\
\hline Experience & & & \\
\hline & 0-10 Years & 103 & 40.9 \\
& $11-20$ Years & 74 & 29.4 \\
& 21-30 Years & 48 & 19.0 \\
& 31+ Years & 27 & 10.7 \\
\hline Subject Matter & & & \\
\hline & Classroom Teachers & 128 & 50.8 \\
& Turkish Language & 36 & 14.3 \\
& Foreign Language & 19 & 7.5 \\
& Science and Technology & 15 & 6.0 \\
& Social Studies & 12 & 4.8 \\
& ICT Education & 12 & 4.8 \\
& Religion Culture and Ethics & 6 & 2.4 \\
& Technology and Design & 8 & 3.2 \\
& Pre-School Education & 3 & 1.2 \\
& Visual Arts & 8 & 3.2 \\
& Psychological Counseling & 5 & 2.0 \\
\hline & Total & 252 & \\
\hline
\end{tabular}

\section{Data Gathering Instrument}

The instrument utilized to gather data in the current study included two parts. The first part included 12 Likert-type items aimed to assess participants' confidence levels in using educational technologies and their training backgrounds in using IWB. In order to understand the realistic preparedness toward interactive whiteboards (IWB), the self-efficacy scale was integrated into the instrument. The self-efficacy scale was previously developed in English within the Interactive Technologies in Language Teaching (ITILT) project where the researcher was a manager running the project requirements in Turkey. The consents of the project partners were obtained in order to adapt the scale and use in the current study. The scale part of the instrument included 19 items focusing on the performance benchmarks that teachers should possess to exploit dynamic, manipulable objects of joint reference and annotative tools afforded by the IWB.

The ensure the validity of the self-efficacy scale, an exploratory factor analysis, that was used to describe variability among observed, correlated variables in terms of a potentially lower number of unobserved, uncorrelated variables called factors, was conducted (Buyukozturk, 2002). However, the critical factor to ensure that the data are compatible to the factor analysis 
is Kaiser-Meyer-Olkin (KMO) coefficient. On the other hand, the value and the significance level attributed to Bartlett's sphericity test indicates the relativity of variables. Buyukozturk (2002) posits that there is a need of high KMO value and significant Barlett's sphericity test result of data to proceed with factor analysis.

The results (KMO=0.96; $X^{2}=8299,314 ; s d=171 ; p=0.00$ ) verified that the data set possess the assumptions of the factor analysis. Besides, a principal component analysis revealed that the instrument includes two factor with an Eigenvalue higher than 1 and the total variance is 84.51. Since the items having high load values more than one item is labeled as overlapped and are suggested to remove from the analysis (Buyukozturk, 2002), the instrument was checked whether there are any overlapping and/or items with load values higher than .30. The factor analysis was finalized since there were no items having higher load values more than proposed rate or overlapped.

As one of the critical steps of factor analysis, to decide on the number of factors in the instrument Kaiser's measurement and Scree plot techniques were utilized. According to Kaiser's measurement, factors having an Eigenvalue which is equal and/or over 1.00 remain in the analysis (Buyukozturk, 2002). The Varimax rotation analysis also indicated that there observed two factors explaining the $84.51 \%$ of the change in the data and having an Eigenvalue more than 1.00. The scree plot graphic given below was obtained within the factor analysis and used to visualize error factors. Kahn, (2006) recommends to exploit multi benchmarks to decide on the number of the factors. Both the scree plot and Kaiser value indicate that the instrument measures two factors. The results portraying the instruments' factor structure were shown and tabulated below (see Figure 1 and Table 2).

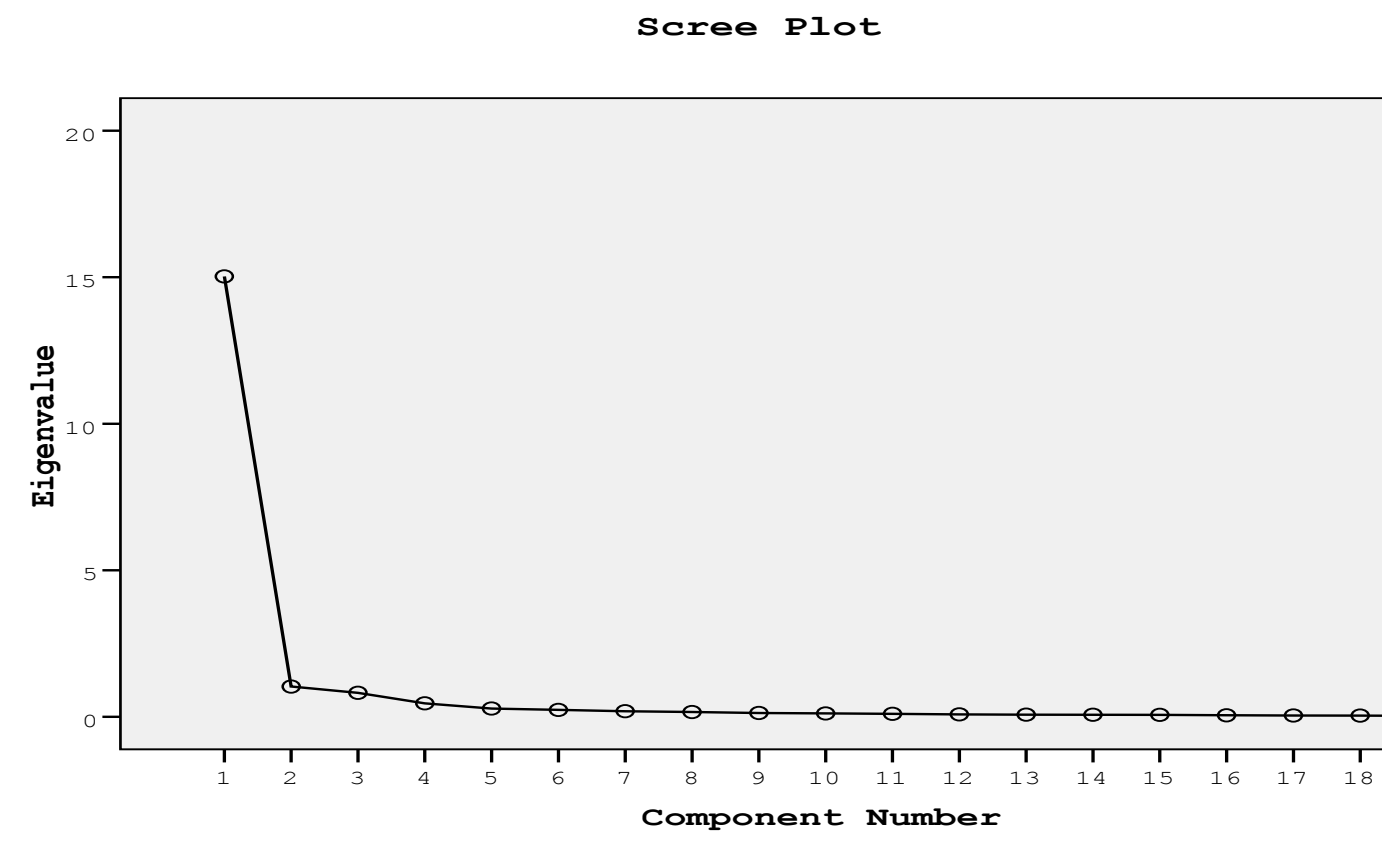

Figure 1. Scree Plot 
Table 2. Results of the Factor Analysis

\begin{tabular}{lccc}
\hline & Items & \multicolumn{1}{c}{ Factors } \\
\hline & & 1 (Common Tools) & 2 (Specific Attributes) \\
\hline Item 8 & .876 & \\
Item 10 & .849 & \\
Item 9 & .832 & \\
Item 6 & .829 & \\
Item 7 & .826 & \\
Item 19 & .788 & \\
Item 11 & .778 & \\
Item 16 & .759 & \\
Item 15 & & .754 & \\
Item 17 & & .753 & \\
Item 18 & & .753 & .883 \\
Item 13 & & .751 & .879 \\
Item 14 & & .738 & .771 \\
Item 12 & & .717 & .698 \\
& Item 2 & & \\
& Item 1 & & \\
& Item 3 & & \\
& Item 4 & & \\
& Item 5 & & \\
\hline
\end{tabular}

The results also pointed out that the first factor, named as common tools, includes the tools which are common among other e-learning software such as flash and captivate. The second factor, named as specific attributes, includes the specific tools and features belong to interactive whiteboard technology. To sum up, the instrument consists of two factors and 19 items of which load values vary between .698 and .883 . Table 3 depicts the each factor's Eigenvalue and the explained variance.

Tablo 3. Self-Value and Explained Variance after Varimax Rotation Test

\begin{tabular}{cccc}
\hline Factors & Eigenvalue & Explained Variance & Total Explained Variance \\
\hline 1 & 9.67 & 50.94 & 50.94 \\
2 & 6.37 & 33.56 & 84.51 \\
\hline
\end{tabular}

The statistical outcomes of the factor analysis indicated that the instrument is regarded as a valid data collection instrument.

Beside the exploratory factor analysis conducted to ensure the construct validity of the scale, a confirmatory factor analysis was applied via LISREL Software to see how the observed data fit into the model including two factors. Confirmatory factor analysis is used to test whether measures of a construct are consistent with a researcher's understanding of the nature of that construct/factor (Simsek, 2007).

Chi-square $\left(X^{2}\right)$ is the most leading good fit index among those used in the filed of structural equation models (SEM). The way to define the models' fit into the model is the calculation of 
the Chi-square's ratio to degree of freedom. Kline (2010) maintains that a ratio of five or below is acceptable. The most widely used good fit indexes which were exploited in the current study are; Goodness of Fit Index, (GFI), Adjusted Goodness of Fit Index, (AGFI), Root Mean Square Residual, (RMR), Root Mean Square Error of Approximation (RMSEA), and Comparative Fit Index, (CFI). A rate of GFI, AGFI, NFI, NNFI and CFI at and/or over .90 indicates a good fit; a rate of RMR or RMSEA below .05 indicates a perfect fit, a rate of .08 and below means an acceptable fit (Schermelleh-Engel, Moosbrugger \& Müler, 2003; Simsek, 2007; Sumer, 2000).

Confirmatory factor analysis was conducted via LISREL Software to see how the observed data fit into the model with two factors on the correlation matrix including 19 items. The good fit indexes shown in Table 4 point out a moderate fit into the proposed model.

Table 4. Good Fit Indexes Caculated for the Factor Structure of the Scale

\begin{tabular}{lc}
\hline Goodness of fit indexes & Value \\
\hline$X^{2} /$ sd $(257,6 / 151)$ & 1.70 \\
GFI & .94 \\
AGFI & .92 \\
CFI & .94 \\
NFI & .91 \\
NNFI & .92 \\
RMR & .06 \\
RMSEA & .04 \\
\hline
\end{tabular}

The calculation of $\left(\mathrm{X}^{2} / \mathrm{sd}\right)$ ratio revealed a 1.70 value which means that the proposed model is in a good fit with the data (Simsek, 2007; Sumer, 2000). The results given in the brackets also indicate that the scale is acceptable with its two factors and valid outcomes (GFI: .94, AGFI: .92, CFI: .94, NFI: .91, NNFI: .92; RMR: .06, and RMSEA: .04). The item-factor relations derived from the confirmatory factor analysis are presented below in Figure 2.

The figure implies that the observed data fit well into the model including two factors. Path coefficients vary between .84 and .95 both which are over .60 and acceptable (Kline, 2010). Thus, confirmatory factor analysis verified the scale's two factor structure. The following section is devoted to the descriptives depicting the participants' responses to the data collection instrument including the scale discussed here. 


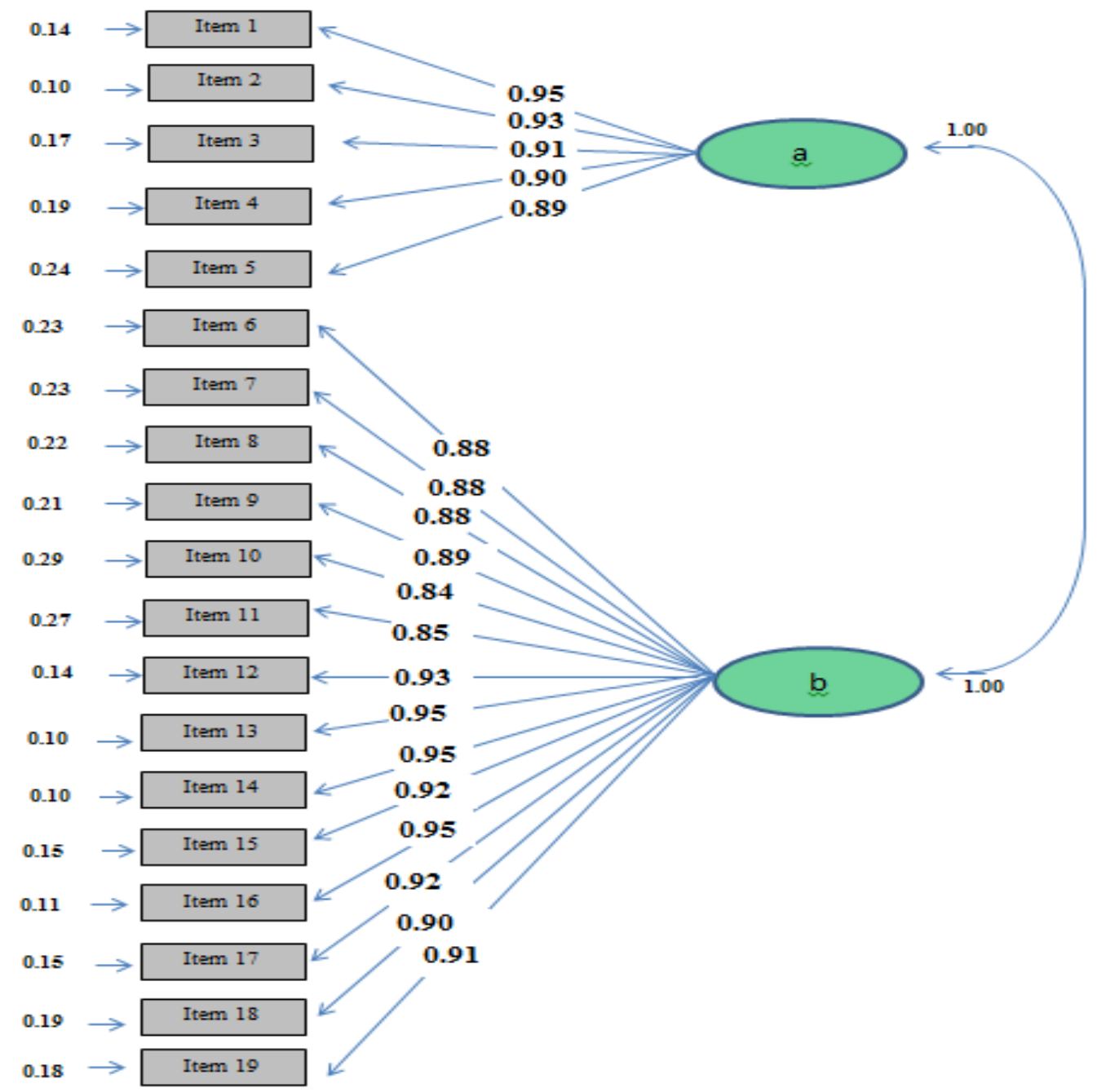

Figure 2. Factor-Item Relation of the Scale

\section{Data Analysis}

While the collected data were analyzed using the descriptive statistics, the overall reliability of the instrument was measured as .89 (Cronbach's Alpha). Table 5 portrays the respondents' self-efficacy levels toward current technologies in education.

Table 5. Descriptives of Participants`Self-Efficacy Levels toward Current Technologies and Training Backgrounds on IWBs

\begin{tabular}{llrr}
\hline & & $\bar{X}$ & SD \\
\hline 1. I am very confident using Tablet PCs for my own purposes. & 3.57 & 1.23 \\
2. I am very confident using Internet for my own purposes. & 3.88 & 1.17 \\
3. I am very confident using systems to keep track of relevant WebPages for & & \\
& my own use (e.g. Favorites, other bookmarking). & 3.71 & 1.14 \\
4. I am very confident using Email for my own use. & 3.70 & 1.22 \\
\hline
\end{tabular}




\begin{tabular}{llll}
\hline 5. I am very confident using social networking sites for my own use. & 3.61 & 1.18 \\
6. I am very confident using Office software for my own use. & 3.54 & 1.13 \\
7. I am very confident using ready-made teaching materials. & 3.72 & 1.01 \\
8. I am very confident adapting content to use as teaching materials. & 3.61 & 1.00 \\
9. I am very confident designing my own teaching materials with the IWB. & 2.80 & 1.02 \\
10. I have received adequate training on how to use the IWB in school. & 2.43 & 1.34 \\
11. I have received adequate training on how to use the IWB outside school. & 2.96 & 1.31 \\
12. I find it easy to locate appropriate resources for teaching with the IWB. & 2.34 & 1.36 \\
\hline
\end{tabular}

Scale: 1=Strongly Disagree 2=Disagree 3=No opinion 4=Agree 5=Strongly Agree

The results provided above can be viewed in three groups as very high, medium, and comparatively low rates. The very high rates are observed within the items focusing on general components of web technologies such as Internet (3.88), navigating tools (3.71), and e-mail services (3.70). Comparing to both higher and lower values, the medium level competences are observed as social media (3.61), office applications (3.54), and tablet PCs (3.57) which are one of the core points of the technology reform movement in the Turkish educational settings. Interestingly, the lowest rates were observed within those related to teachers' self-efficacy thoughts on designing their own teaching materials with IWB and locating appropriate resources for teaching with the IWB. Relatively, participants declared that their trainings on using IWB is not satisfactory. Table 6 informs on participants' self-efficacy levels on using the features of IWB in classroom teaching.

Table 6. Participants`Confidence Levels of IWB Use in Teaching

\begin{tabular}{|c|c|c|c|c|c|}
\hline & \multirow[t]{2}{*}{ I am very confident in using.. } & \multicolumn{2}{|c|}{$\begin{array}{l}\text { I do not know } \\
\text { what this is. }\end{array}$} & \multicolumn{2}{|c|}{ Likert Scale } \\
\hline & & $F$ & $\%$ & $\overline{\mathrm{X}}$ & SD \\
\hline 1. & the pen tool & 25 & 10.0 & 2.85 & 1.13 \\
\hline 2. & the eraser tool & 25 & 10.0 & 2.86 & 1.12 \\
\hline 3. & the handwriting recognition tool & 26 & 10.4 & 2.73 & 1.11 \\
\hline 4. & the floating or on-screen keyboard & 24 & 09.6 & 2.86 & 1.12 \\
\hline 5. & the thought/speech bubbles tool & 25 & 10.0 & 2.75 & 1.05 \\
\hline 6. & the split screen tool & 28 & 11.2 & 2.67 & 1.05 \\
\hline 7. & the highlighter tool & 27 & 10.8 & 2.67 & 1.05 \\
\hline 8. & the shading tool & 30 & 12.0 & 2.64 & 1.07 \\
\hline 9. & the underlining tool & 27 & 10.8 & 2.73 & 1.06 \\
\hline 10. & the spotlight tool & 34 & 13.6 & 2.60 & 1.07 \\
\hline 11. & the hide and reveal tool & 27 & 10.8 & 2.68 & 1.08 \\
\hline 12. & the IWB to drag and drop text and/or images & 27 & 10.8 & 2.77 & 1.09 \\
\hline 13. & the IWB to play audio files & 28 & 11.2 & 2.78 & 1.12 \\
\hline 14. & the IWB to play video clips & 27 & 10.8 & 2.72 & 1.10 \\
\hline 15. & the IWB to insert images or diagrams & 29 & 11.6 & 2.73 & 1.10 \\
\hline 16. & the IWB to create graphs/charts/tables & 27 & 10.8 & 2.65 & 1.06 \\
\hline 17. & the IWB to save students' work & 29 & 11.6 & 2.74 & 1.10 \\
\hline 18. & the IWB to print off students' work & 28 & 11.2 & 2.75 & 1.09 \\
\hline 19. & $\begin{array}{l}\text { additional IWB-related devices such as slates or } \\
\text { ActiVote }\end{array}$ & 31 & 12.4 & 2.66 & 1.11 \\
\hline
\end{tabular}

Scale: 1=Strongly Disagree 2=Disagree 3=No opinion 4=Agree 5=Strongly Agree 
The results shown in Table 6 describe two different groups of data. The first group explains the frequencies and percentages of those respondents who declares they have never heard about the tool or feature being asked in the item. The second group of data elaborates on the confidence levels of the participants in using various tools and features of IWBs. According to the rates observed in the first group, nearly all items received similar percentages of responses between 9.6 and 13.6. A variation was observed among the rates though, a slight discrepancy occurred between the items received comparatively low and high rates. That is to say, pen $(10.0 \%)$, eraser (10.0\%), handwriting (10.4), and on-screen keyboard (9.6\%) tools were checked comparatively lower than sportlight (13.6\%), activeslate/vote (12.4), and shading $(12.0 \%)$ tools. As for the second group of results, a similar discrepancy emerged on the items received low and high confidence rates. The items belonging to the first factor were received higher means which means the participants are more confident in using these tools. However, some of the items belonging to the second factor were rated comparatively lower which indicates a low confidence in actual use. The following part will focus on the discussion of the findings in the scope of the current study.

\section{Discussion and Conclusion}

In order to get a profound view of teachers' IWB related competencies, a self-efficacy scale was adapted in Turkish by applying exploratory and confirmatory factor analyses. The adaptation studies of the scale revealed that it includes two factors with acceptable KMO and Barlett's sphericity test values. The factors emerged through the scale were implied as common and specific tools of IWBs.

Results of the preliminary items in the survey posit that the concrete self-efficacy in using general technologies such as Internet, e-mail, and web tools tend to diminish while the educational and IWB related technologies are being questioned. Related studies have shown that IWBs foster students' motivation and involvement in learning activities because the interactive components attract their attention and increase concentration (Marzano, 2009; Schmid, 2008; Slay et al., 2008; Smith, Higgins, Wall, \& Miller, 2005). However, teachers' attitudes and technological skills, and, most importantly, instructors' careful planning of IWB lesson activities heavily determines the motivational profits (Glover, Miller, Averis, \& Door, 2007; Holmes, 2009; Torff \& Tirotta, 2010). Therefore, training teachers to become familiar with IWB technology and to understand the best ways to use it are critical to assure the quality of technology integration in classrooms.

The results of this research show that the participant teachers, in general, are in need of attending IWB training workshops. As Slay et al. (2008) argue, changing pedagogical understanding and common practices is vital to make optimal use of the promising interactive technology tool. Since the IWBs will soon be an essential ICT tool in the Turkish educational settings, the training workshops may provide opportunities for teachers to physically interact with IWB hardware and software, and to consider the pedagogical aspects of IWB use. Training workshops serve as a medium to help teachers to gain skills and confidence with the IWB technology which might boost their independent and self-directed learning nature, according to adult learning theory (Merriam et al., 2007).

In terms of participants` awareness towards IWB tools and features, a little (nearly $10 \%$ ) group of them declared their ignorance. This result indicates that a large body of the participants 
were at least aware of IWB tools and features in a way. As one of the core points of the current study, the confidence levels of the participants in using IWB tools and features were observed as very consistent through the scale. All of the items in the scale part of the survey were found out as in the category of 'disagree' as an indicator of participants' low self- efficacy levels in using IWB components. However, a slight discrepancy also emerged between the common and sophisticated IWB tools and features. In general, therefore, it seems that participated teachers do not rate themselves as competent IWB users as the most obvious finding to emerge from this study.

These findings enhance our understanding of how IWB should be incorporated into the actual teaching environments or teacher training programs. This research will serve as a bassis for future studies and contribute into enhancing opportunities to utilize educational technology. However, a number of caveats need to be noted regarding the present study. The current investigation was limited by a small sample size which prevents the results 'transferability to the general competence levels of the teachers and/or all teachers occupied in similar contexts. Another limitation of the study was having the same group of participants in both phases of the instrument's validation processes. Besides, the current study has only examined the selfreported confidence levels of the teachers. Additionally, since the ITILT project is still going on, there is no concrete information on the validity of the original form of the instrument. This research has thrown up many questions in need of further investigation.

The further research should focus on active performances of teachers while exploiting IWB technology in facilitating learning through various tasks including interactivity. Capturing the efficient use of IWB in actual teaching from various learning disciplines would provide insight to all stakeholders of educational technology. Further experimental investigations are needed to estimate the motivational effects of IWB in learning process.

\section{References}

Baran, B. (2010). Experiences from the process of designing lessons with interactive whiteboard: ASSURE as a road map. Contemporary Educational Technology, 1(4), 367380.

Becta (2008). Harnessing technology schools survey 2007. Retriewed on 10 Jan 2011 from http://research.becta.org.uk/index.php?catcode=_re_rp_02\&rid=14110\&section=rh

Buyukozturk, S. (2002). Sosyal bilimler icin veri analiz el kitabi [Handbook for data analysis in social sciences]. Ankara: Pegem.

CutrimSchmid, E. (2007). Enhancing performance knowledge and self-esteem in classroom language learning: The potential of the ACTIVote component of interactive whiteboard technology. System, 35(2), 119-133.

CutrimSchmid, E. (2008). Using a voting system in conjunction with interactive whiteboard technology to enhance learning in the English language classroom. Computers \& Education, 50(1), 338-356.

Dobrovolny, J. (2006). How adults learn from self-paced, technology-based corporate training: New focus for learners, new focus for designers. Distance Education, 27(2), 155-170. 
Dwyer, J. (2007). Computer-based learning in a primary school: Differences between the early and later years of primary schooling. Asia-Pacific Journal of Teacher Education, 35(1), 89103.

Erduran, A., \& Tataroglu, B. (2010) Comparison of the science and mathematics teachers' opinions on the usage of interactive whiteboard in education. $9^{\text {th }}$ International Educational Technology Conference (IETC2009). Ankara.

Glover, D., \& Miller, D. (2002). The introduction of interactive whiteboards into schools in the United Kingdom: Leaders, led, and the management of pedagogic and technological change. International Electronic Journal for Leadership in Learning, 6(24). Retrieved on 15 November 2010 from http://www.ucalgary.ca/iejll/glover_miller

Glover, D., Miller, D., Averis, D., \& Door, V. (2007). The evolution of an effective pedagogy for teachers using the interactive whiteboard in mathematics and modern languages: An empirical analysis from the secondary sector. Learning, Media and Technology, 32(1), 520.

Gray, C., Hagger-Vaughan, L., Pilkington, R., \& Tomkins, S. (2005). The pros and cons of interactive whiteboards in relation to the key stage 3 strategy and framework. Language Learning Journal, 32, 38-44.

Gulbahar, Y. (2007). Technology planning: A Roadmap to successful technology integration in schools. Computers and Education, 49(4), 943-956.

Hall, I. \& Higgins, S. (2005). Primary school students' perception of interactive whiteboard. Journal of Computer Assisted Learning, 21, 102-117.

Hennesey, S., Ruthven, K., \& Brindley, S. (2005). Teacher perspectives on integrating ICT into subject teaching: commitment, constraints, caution and change. Journal of Curriculum Studies, 37(2), 155-192.

Hennessy, S., Deaney, R., Ruthven, K., \& Winterbottom, M. (2007). Pedagogical strategies for using the interactive whiteboard to foster learning participation in school science. Learning, Media and Technology, 32(3), 283-301.

Higgins, S., Beauchamp, G., \& Miller, D. (2007). Reviewing the literature on interactive whiteboards. Learning, Media and Technology, 32(3), 213-225.

Holmes, K. (2009). Planning to teach with digital tools: Introducing the interactive whiteboard to pre-service secondary mathematics teachers. Australasian Journal of Educational Technology, 25(3), 351-365.

Hooper, S. \& Rieber, L. (1995). Teaching with technology. In A. Ornstein (Ed.), Teaching: Theory into practice (pp. 154-170). Boston, MA: Allyn and Bacon.

Jones, S. \& Tanner, H. (2002). Teachers' interpretations of effective whole-class interactive teaching in secondary mathematics classrooms. Educational Studies, 28(3), 265-274.

Kennewell, S., Tanner, H., Jones, S., \& Beauchamp, G. (2008). Analysing the use of interactive technology to implement interactive teaching. Journal of Computer Assisted Learning, 24, 61-73.

Kerr, S. T. (1991). Lever and fulcrum: educational technology in teachers' thought and practice. Teachers College Record, 93(1), 114-136.

Kline, R. B. (2010). Principles and practice of structural equation modeling (3rd edition). New York: Guilford. 
Lai, H. J. (2010). Secondary school teachers' perceptions of interactive whiteboard training workshops: A case study from Taiwan. Australasian Journal of Educational Technology, 26, 511-522.

Lam, Y. \& Lawrence, G. (2002). Teacher-student role redefinition during a computer-based second language project: Are computers catalysts for empowering change? Computer Assisted Language Learning, 15(3), 295-315.

Levy, P. (2002). Interactive whiteboards in learning and teaching in two Sheffield schools: A developmental study. Department of Information Studies, University of Sheffield. Retrieved on 9 April 2011 from http://dis.shef.ac.uk/eirg/projects/wboards.htm.

Littleton, K., Twiner, A., Gillen, J., Kleine S., Judith N., \& Mercer, N. (2007). Orchestration with the interactive whiteboard. Paper presented at the Developing Potentials for Learning 12th Biennial Conference for Research on Learning and Instruction. 28 August 1 September 2007. University of Szeged, Budapest. Retrieved on 17 January 2012 from http://oro.open.ac.uk/ 15279/2/EARLI_August_22ndHO.pdf

Littleton, K. (2010). Research into teaching with whole-class interactive technologies: Emergent themes. Technology, Pedagogy and Education, 19(2), 285-292.

Marzano, R. J. (2009). Teaching with interactive whiteboards. Educational Leadership, 67(3), 80-82.

Merriam, S. B., Caffarella, R. S., \& Baumgartner, L. M. (2007). Learning in adulthood: A comprehensive guide (3rd edition). San Francisco, CA: John Wiley \& Sons.

Murphy, J. F., Jain, N. L., \& Spooner, S. A. (1995). Use of an interactive electronic whiteboard to teach clinical cardiology decision analysis to medical students. Journal of the American College of Cardiology, 25(2), 238.

Niederhauser, D. \& Stoddart, T. (2001). Teachers' instructional perspectives and use of educational software. Teaching and Teacher Education, 17(1), 15-31.

Northcote, M. \& Marshall, S. (2010). Interactive whiteboards: Interactive or just whiteboards? Australasian Journal of Educational Technology, 26(4), 494-510.

Olson, J. (2000) Trojan horse or teacher's pet? Computers and the culture of the school. Journal of Curriculum Studies, 32(1), 1-8.

Quashie, V. (2009). How interactive is the interactive whiteboard? Mathematics Teaching, 214, 34- 38.

Saltan, F., Arslan, K. \& Gok, A. (2010) Teachers' acceptance of interactive white boards: A case study. In D. Gibson \& B. Dodge (Eds.), Proceedings of Society for Information Technology \& Teacher Education International Conference, 2010 (pp. 2360-2365). Chesapeake, VA: AACE.

Schmid, E. C. (2006). Investigating the use of interactive whiteboard technology in English language classroom through the lens of critical theory of technology. Computer Assisted Language Learning, 19(1), 47-62.

Schmid, E. C. (2008). Potential pedagogical benefits and drawbacks of multimedia use in the English language classroom equipped with interactive whiteboard technology. Computers \& Education, 51, 1553-1568. 
Schermelleh-Engel, K., Moosbrugger, H., \& Muller, H. (2003). Evaluating the fit of structural equation models: Tests of significance and descriptive goodness-of-fit measures. Methods of Psychological Research-Online, 8, 23-74.

Simsek, O. F. (2007). Yapısal esitlik modellemesine giris: Temel ilkeler ve LISREL uygulamalari (Introduction to structural equation modeling: Basic principles and LISREL applications). Istanbul: Ekinoks.

Slay, H., Sieborger, I., \& Hodgkinson-Williams, C. (2008). Interactive whiteboards: Real beauty or just "lipstick"? Computers \& Education, 51, 1321-1341.

Smith, H. J., Higgins, S., Wall, K., \& Miller, J. (2005) Interactive whiteboards: boon or bandwagon? A critical review of the literature. Journal of Computer Assisted Learning, 21(2), 91-101.

Somyurek, S., Atasoy, B., \& Ozdemir, S. (2009). Board's IQ: What makes a board smart? Computers \& Education, 53(2), 368-374.

Stephens, C. D. (2000). Forget the sailboard--let's go whiteboarding! Dental Update, 27(5), 236-240.

Sumer, N. (2000). Yapısal esitlik modelleri: Temel kavramlar ve ornek uygulama. Turk Psikoloji Yazilari, 3(6), 49-73.

Torff, B. \& Tirotta, R. (2010). Interactive whiteboards produce small gains in elementary students' self-reported motivation in mathematics. Computers \& Education, 54, 379-383.

Turel, Y. K. (2011). An interactive whiteboard student survey: Development, validity and reliability. Computers \& Education, 57, 2441-2450.

Turel, Y. K. \& Demirli, C. (2010). Instructional Interactive Whiteboard Materials: Designers' Perspectives, Procedia Journal of Social and Behavioral Sciences, 9, 1437-1442.

UNESCO (2010). Government of Australia invests $\$ 40$ million (AUD) for teachers' ICT training. Retrieved on 10 January 2012 from http://www.unescobkk.org/information/newsdisplay/article/government-of-australiainvests- 40-million-aud-for-teachers-ict-training/

Wall, K., Higgins, S., \& Smith, H. (2005). The visual helps me understand the complicated things: Student views of teaching and learning with interactive white boards. British Journal of Educational Technology, 36(5), 851-867.

Wood, R. \& Ashfield, J. (2008). The use of the interactive whiteboard for creative teaching and learning in literacy and mathematics: A case study. British Journal of Educational Technology, 39(1), 84-96.

Wu, C., \& Lin, C. (2009). A study of using interactive whiteboards at elementary school (in Chinese). Life Technology Education Journal, 42(6), 14-25.

Xu, H. L., \& Moloney, R. (2011). Perceptions of interactive whiteboard pedagogy in the teaching of Chinese language. Australasian Journal of Educational Technology, 27(2), 307-325.

Zevenbergen, R., \& Lerman, S. (2008). Learning environments using interactive whiteboards: new learning spaces or reproduction of old technologies. Mathematics Education Research Journal, 20(1), 107-125.

Correspondence: Serkan Celik, Assistant Professor, Department of Computer Education and Instructional Technologies, Faculty of Education, Kirikkale University, Kirikkale, Turkey 